\title{
Migraciones Visuales: análisis del fenómeno migratorio a través del videoarte
}

\author{
Célia Riboulet*
}

\begin{abstract}
Resumen
Este ensayo explora los modos en los que la migración se desplaza (en el espacio y en el tiempo) a través de las problemáticas relativas a la habitación (la casa), lengua, memoria, identidad y arquitectura. También analiza las diferentes modificaciones que generan los desplazamientos en diferentes tiempos y territorios. Porque "el arte contemporáneo se encuentra en la frontera que separa la información de la ficción, frontera entre el documental y la puesta en abismo de nuestra sociedad" (Renard, 2007, p.17) y está elegido (y más específicamente el videoarte) como soporte posible para el análisis del tema estudiado: migraciones. Las nociones de fronteras, territorios, exilios, cuestionamientos identitarios y espaciales están en medio de los procesos artísticos de varios artistas "migrantes" o "no migrantes". Algunos rechazan la definición de artista migrante, no obstante sus historias personales nutren sus creaciones; otros "no migrantes" han tratado el tema como un fenómeno de relevante importancia política, social, histórica, etc. Palabras claves: Migración. Espacio. Tiempo. Videoarte. Globalización.
\end{abstract}

\section{Visual migrations: analysis of migration through video art Abstract}

This paper explores the manners in which the migration moves (in the space and in the time) across the problematic relative to the house, to the language, to the memory, to the identity and to the architecture. It analyzes the different modifications that generate the displacements in different times and territories. Because "the contemporary art is on the border that separates the information of the fiction, border between the documentary and the position in abyss of our society (Renard, 2007, p.17)", this one chosen (specifically the 'videoart') as possible support for the analysis of the topic: migrations. The notions of

\footnotetext{
* Profesora maestra en Licenciatura de Arte Digital, Centro Nacional de las Artes, Facultad de Artes, de la Universidad Autónoma del Estado de México, Chalmita - Ocuilan - Estado de México, MX. E-mail: ribouletcelia@gmail.com
} 


\section{CÉLIA RIBOULET}

borders, territories, exiles, questions of identity, spatial are in the middle of the artistic processes of several artists "migrants" or not. If several reject the artist's definition migrant, nevertheless their personal histories nourish their creations, others "not migrants" treated the topic as a phenomenon of relevant political, social, historical importance.

Keywords: Migration. Space. Time. Videoarte. Globalization.

\section{Migrações visuais: análise do fenômeno migratório por meio da chamada 'vídeoarte' \\ Resumo}

Este estudo explora os modos pelo qual a migração se desloca (no espaço e no tempo) por meio de problemáticas relativas a habitação (casa), língua, memória, identidade e arquitetura. Também analisa as diferentes modificações que geram os deslocamentos em diferentes tempos e territórios. Isso porque "a arte do contemporâneo se encontra na fronteira que separa a informação da ficção, fronteira entre o documenta e a posição de abismo de nossa sociedade (Renard, 2007, p.17)" e está colocada (mais especificamente na "vídeoarte") como suporte possível para a análise do tema estudado: migrações. As noções de fronteiras, territórios, exílios, questionamentos identitários e espaciais estão em meio a processos artísticos de vários artistas "migrantes" ou "não migrantes". Alguns reforçam a definição de artista migrante, não obstante suas histórias pessoas "não migrantes" nutrem suas criações; outros "não migrantes" têm tratado o tema como um fenômeno de relevância política, social, histórica.

Palavras chave: Migração. Espaço. Tempo. Vídeo arte. Globalização.

\section{Introducción}

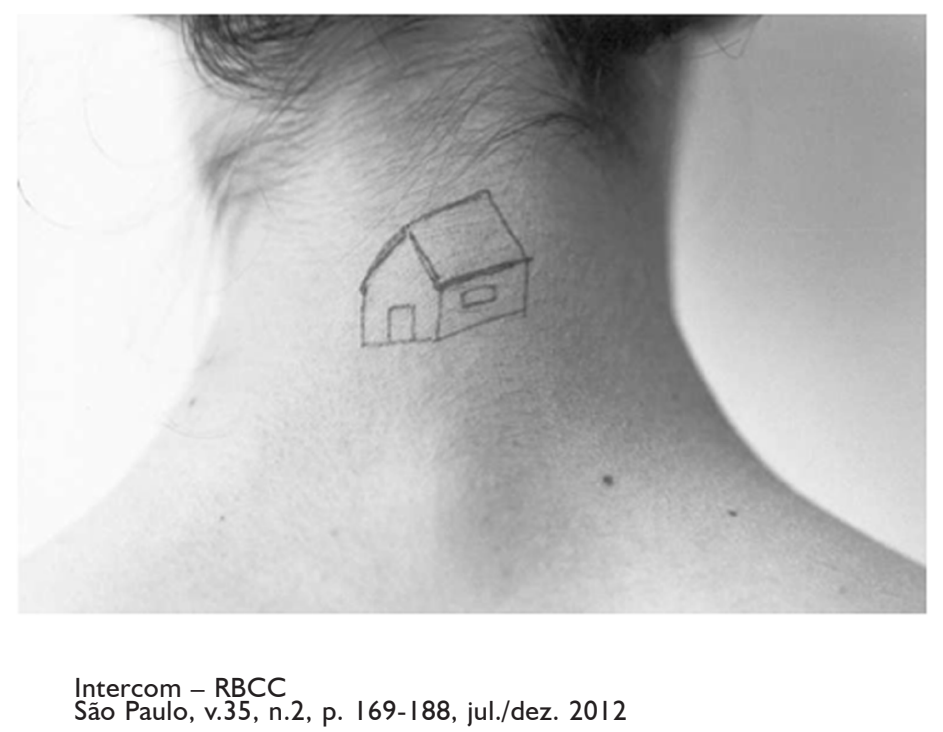


L

as migraciones internacionales son una de las formas más antiguas de la mundialización que se encuentra en uno de los puntos de articulación de lo global y local, cristalizando muchas interrogantes y angustias actuales. Nuevas configuraciones migratorias aparecen en el desplazamiento, con la diversificación e internacionalización de los flujos que revelan los disfuncionamientos, las mutaciones, las angustias y las esperanzas del mundo. De allí su fuerte carga simbólica y política para que los artistas se asuman como tales y como actores sociales.

Este artículo analiza de manera parcial el trabajo de algunos artistas que tratan el tema de la migración a través del video. Esta noción de migración se presenta bajo varias facetas. Dentro de las suposiciones, mostraré que aunque entendemos principalmente la cuestión de la migración en términos espaciales, ésta se realiza consecuentemente en términos temporales. La migración entendida en estricto sentido de "pasar de un lugar a otro lugar" implica precisamente problemáticas identitarias que se consolidan alrededor del tema de la casa, del paisaje, del tiempo, del olvido, del alejamiento. Trazaré una cartografía de las diferentes problemáticas presentes en este fenómeno global por medio de las obras de Tomás Ochoa, Zined Sedira, Gautam Kansara, Daniel Lupion, Doug Aitken. Para lograr el objetivo, seguiré lo propuesto por Bruno Latour en su libro: La ciencia en acción, en el que se refiere a las investigaciones en ciencias sociales y humanidades en la actualidad, evidenciando que el investigador debe estar inmerso en el fenómeno a investigar; esto lo asumo como creadora de videoarte. Por otro lado considero pertinentes los conocimientos de Nicolas Bourriaud referentes a la estética relacional ${ }^{1}$, en los que propone la necesidad de establecer una serie de dispositivos que sirvan como puntos de partida para determinar el rumbo a seguir en la investigación. Desde esta visión metodológica se formularán los dispositivos necesarios para abordar las propuestas artísticas mencionadas.

Esta investigación se construye sobre el análisis de obras de carácter videográfico (instalaciones o monocanal) producidas desde 2002 hasta 2010 por artistas migrantes o no-migrantes.

\footnotetext{
${ }^{1}$ Nicolás Bourriaud refirió el término: Estética relacional (Esthétique relationnelle), en su libro publicado en París en 2000.
}

Intercom - RBCC

São Paulo, v.35, n.2, p. 169-188, jul./dez. 2012

$|7|$ 


\section{CÉLIA RIBOULET}

Las obras, realizadas por artistas de diferentes nacionalidades, no fueron elegidas en base a una delimitación geográfica, sino a partir de una experiencia. La del migrante, cuya trayectoria no se centra específicamente en problemáticas sociohistóricas y políticas particulares sino en prácticas cotidianas (iComo las obras nos pueden hablar de este estado que vive el hombre a través del "transitar", del migrar?)

\section{Identidad y migración}

Tentativamente, podríamos, a modo de preámbulo, citar el video Mirror del artista ecuatoriano Tomás Ochoa². Grabado a las 4 de la mañana en el Consulado Americano de Guayaquil en Ecuador, el video, bajo la forma de la entrevista, pregunta a diferentes personas: “iDe qué raza es usted?" Simple cuestión que levanta, a lo largo de sus respuestas, problemáticas identitarias complejas.

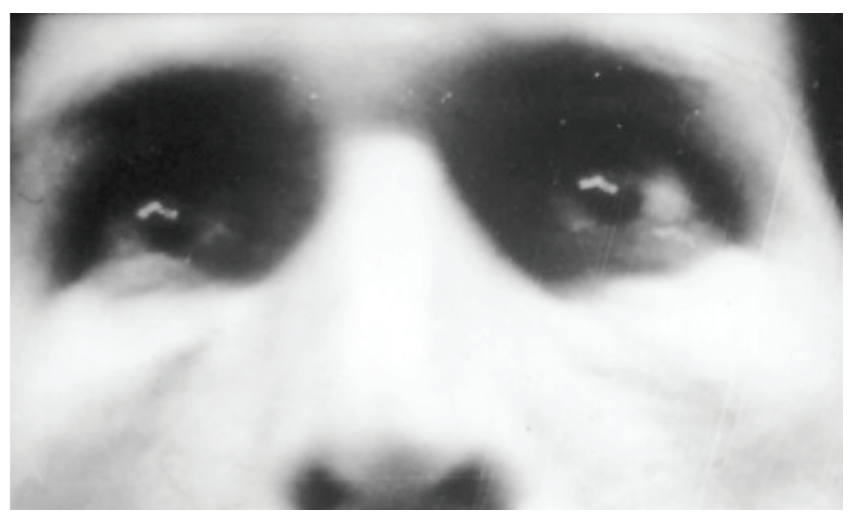

Una muestra de las respuestas: "Mestiza. Blanca. Yo soy de Cuenca. Mestiza. Blanca. Una mezcla de puruah y español. Blanca. Cuencano. No sé. No sé. Cholo. Mestiza..."

Evidentemente, la sencillez de la pregunta no implica que la respuesta sea igual. Sobre todo, esta heterogeneidad de la respuesta se desarrolla en un espacio específico (el Consulado americano en

${ }^{2}$ OCHOA, Tomás, Mirror, (Video), 2002, 1 Channels, 1min. 45sec, son., BN. Disponible en:

http://www.tomasochoa.com/works/MIRROR/Mirror.html

172

Intercom - RBCC

São Paulo, v.35, n.2, p. 169-188, jul./dez. 2012 
Guayaquil, Ecuador); espacio que simboliza otra potencia, otro imperialismo, otra colonización (contando la colonia española): la de los Estados Unidos. Esta misma heteregenidad se desarrolla entorno a una doble espiral que se determina en función del punto de partida y llegada. Si en primera parte esta multiplicidad de respuestas remite a lo que fue la colonización, también remite a lo que llamé el punto de llegada, que sería: la aspiración futura del entrevistado. Por aspiración entendemos sus deseos, proyectos, con los cuales se identifica él y sus deseos. Por ejemplo, la persona que responde "mestiza" valoriza su carácter indígena, mientras la que se dice de raza blanca, valoriza su parte occidental, con vistas a una identificación futura.

Pero todos se encuentran en un mismo deseo, el de MIGRAR. ¿Por qué migrar?

Por persecución, dictadura, genocidios, matanzas, luchas, pobrezas, sueños, ilusiones, deseos. Unos testimonios acompañan fotografías de paisajes "conmemorativos" del artista Oscar Farfán (2009, p.10):

Yo estaba en el patio cuando mataron a mis padres y a mis hermanos mayores. Alrededor de unos trescientos soldados y otros trescientos cincuenta patrulleros vinieron. Yo me hice la muerta, en medio de mis padres me quedé. Yo estaba llena de sangre y sentí que me iba a quemar, no aguanté más y me fui a esconder a la montaña; luego volví y me escondí con los que ya estaban muertos, pero sentí que ya no aguantaba el fuego y regresé a la montaña. Yo tenía como 10 años, me fui con miedo y llorando; me encontré con una tía y me fui con ella. Cuando amaneció regresé al lugar nuevamente y vi a mis padres, estaban todos quemados. Sólo se les veían los dientes, toda la cara la tenían negra. A mi padre y a mi madre los perros ya les estaban comiendo las piernas, y mis hermanos ya no se veía quiénes eran; y yo regresé llorando, ya no había nada qué hacer y me fui. ${ }^{3}$

¿Qué implica la migración? Si migrar designa la acción de "pasar de un lugar a otro lugar", la migración se plantea primeramente en términos de espacios. Existe, por consecuencia, un espacio de ida, uno de transición y uno de llegada.

\footnotetext{
${ }^{3}$ FARFAN, Oscar, Tierra Arrasada, (Video y serie fotografica), 2009-10, son., Color. Disponible en: http://www.oscarfarfan.net/?page_id=214
}

Intercom - RBCC

São Paulo, v.35, n.2, p. 169-188, jul./dez. 2012 
El espacio de ida se compone de elementos conocidos por el migrante, como su familia, trabajo, comunidad, casa, etc. El espacio de transición corresponde al recorrido que realiza el migrante para llegar al punto de llegada, este último se caracteriza quizás por estar más establecido que los espacios recorridos.

\section{Casa y migración}

¿Cómo poder definir si el espacio está o no establecido? ¿Cómo saber si el migrante llegó o no a su punto de llegada? Seguramente existirán muchos puntos de llegada, pero proponemos que uno de los elementos esenciales para definir este estado de estabilidad sea la casa; cuando el migrante construye o se establece en un espacio construido que define como su casa. Es relevante en este caso hacer referencia al sinograma 住, que significa "habitar" en mandarino. Este sinograma está formado por la combinación de dos elementos: el de la izquierda es la clave del hombre, que da el sentido principal; el de la derecha indica la pronunciación, pero tiene también el sentido de "pararse". "Entonces, la idea de habitar representaría la imagen del ser humano que para de caminar" (BERQUE, 2008, p.231), para establecerse en un espacio que llamamos casa.

¿Porque reactivar este termino de "casa" cuando "el tiempo de la casa ya paso" (ADORNO, 1980, p.37)? En la edad de las megalópolis, de los nuevos nomadismos, ya no existiría residencia, domus, pero solamente viviendas, domicilios, refugios decorados llamados "departamentos". Pero este vocablo persiste en la lengua y lo pronunciamos varias veces al día, siempre cuando nos preguntan: ia donde estas? Pues, cuando no estamos en la calle, en el trabajo, en la escuela, en el supermercado o en el metro, estamos en la casa. ¿Como definir la casa? En la idea de Benoît Goetz, la casa no es un concepto (tal idea de arquitectura), ni un objeto empírico (no tiene una forma precisa: puede ser una casa de campana, una cabaña, un departamento). "Considerare más bien la casa como una estructura, entendida como un ritmo y un dinamismo espacio-temporal" (GOETZ, 2011, p.101) En otras palabras, una casa es una manera de habitar el espacio, o 
de poseer un espacio, es decir un modo de habitación. Entonces, es el habitar que construye una casa. "Es solamente habitándola que hacemos realmente de la casa una casa" (HEIDEGGER, 1990, p.51) El sentido topológico, antropológico de la casa se organiza alrededor de la noción de hogar.

Una obra de Tomás Ochoa, intitulada La casa Ideal (2008)4, pregunta (lo deducimos a partir de las respuestas): ¿Como esta su casa ideal?
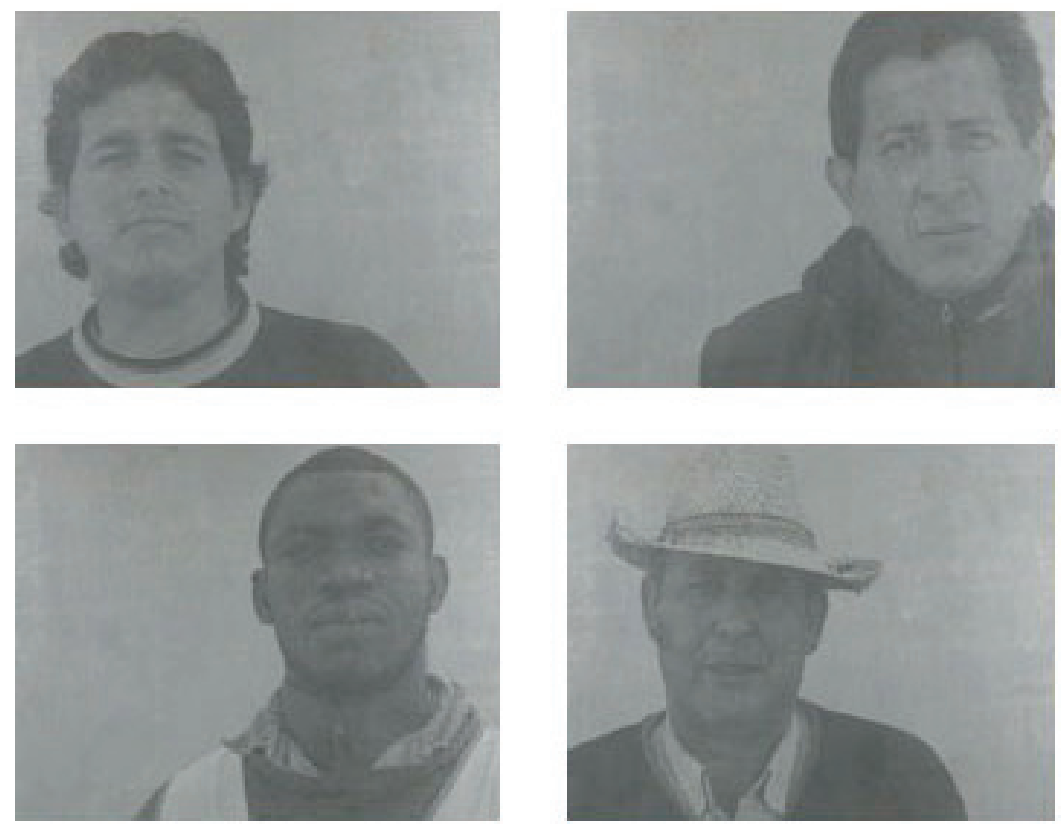

El artista ecuatoriano que vive en Europa realiza este video en España. Los entrevistados son migrantes que describen, de manera detallada, lo que sería su casa ideal. El primer hombre, de aproximadamente 50 años cuenta:

Si me podría construir una casa, la construiría como siempre la he soñado. Al lado de una playa, con una piscina. Pues una casa, como lo dicen en mi

\footnotetext{
${ }^{4}$ OCHOA, Tomas, La casa ideal, (video Instalación), 2008, 1 Channel, 6min., son., NB. Disponible en: http://www.tomasochoa.com/works/LA\%20CASA\%20 IDEAL/Casa.html
} 


\section{CÉLIA RIBOULET}

pueblo, una "casa quinta”. iComo uno quiere vivir! Yo por ejemplo, quiero vivir como un rey. Yo soy una persona de muchos sueños. Y los sueños para mí nunca se pierden. Dicen en mi pueblo que la tierra buena está detrás de las orejas. Entonces pues, es bueno construir una casa ideal tanto aquí como allí. Allí por lo que es fácil construir y aquí porque es difícil pero no imposible (OCHOA, 2008).

En el video, el contraste entre el movimiento de la imagen en blanco y negro (casi fijo) coloca a los personajes en un estado "petrificado" de infinita repetición, y el de la narración provoca un desplazamiento del sentido. Como si uno pertenecería al sueño (la voz) y el otro a la realidad (una imagen estancada entre un pasado y un futuro imprecisos que congelan el presente en una repetición incesante del mismo). La inmovilidad de la imagen tiene como consecuencia poner en duda, o en peligro, la realización y concretización de los sueños entregados. También descontextualiza la voz y la opone o, mejor dicho, la somete a un fragmento de realidad que es la imagen. Imagen reveladora de una condición social difícilmente reversible. No obstante, el entrevistado idealiza doble, es decir, no habla solamente de una casa, sino de dos: una aquí y una allí.

Esta repetición podría parecer una idea exagerada, fortuita. Pero esta distinción toma todo su sentido cuando analizamos un fragmento de un análisis realizado por la antropóloga Frida Calderón-Bony, análisis realizado sobre los espacios domésticos de migrantes del pueblo de Patamban (MICHOACÁN, México, 2009, p.90):

[las casas] espacios que son una representación de la manera en la cual los migrantes simbolizan su movilidad, por un lado, por ellos mismos, en la intimidad de la casa del país de destinación, por otro lado, por la comunidad del grupo de pertenencia, a través del aspecto exterior de la casa en su pueblo.

Esta distinción interior/exterior es muy importante en lo que revela procesos y necesidades distintos.

En el interior de la residencia construida por el migrante, en su país de adopción, el migrante busca rencontrar los signos de su identidad de origen. En este sentido, el interior funciona como un universo de contacto con el lugar abandonado. Simula la puesta en escena de un espacio en el cual los apegos de origen pueden 
presentarse. Su casa gira hacia adentro en búsqueda de su pasado, con el objetivo de dar sentido a su presente. "El recuerdo se vuelve una impresión llena de significación y el interior de la casa constituye justamente la escena de los recuerdos (CALDERÓN. -BONY, 2009, p.95)".

Esta simulación se recrea gracias a una escenografía muy personalizada e íntima: las paredes se ornan de fotografías de la familia viviendo en el pueblo, como de las fotografías de los santos y de otros elementos folklóricos que pertenecen a la tradición local ${ }^{5}$.

Por oposición, la casa que se quiere construir en el país de origen, en el pueblo, representa, según la antropóloga, el principal índice de "logro migratorio", junto con el envío de dinero a la familia y la compra de un automóvil. La construcción de la casa funciona como una presencia espacial que instala un "lenguaje" a través del cual el migrante cuenta sus historias a los miembros de su comunidad, como reflejo de su camino. Cuando uno se va, ¿cómo hacerse ver? ¿Cómo dar sentido al presente que uno vive? La casa es ese objeto que sirve de identificación entre el migrante y el grupo. En este caso lo que va a sobresalir es el exterior, porque una características de estas casas es ser poco utilizadas o estar deshabitadas.

El documental de Taro toma justamente como tema las marcas arquitectónicas de las casas construidas por los migrantes en México. Las particularidades señaladas se reúnen para apuntar las siguientes características: un segundo piso, un estacionamiento, la forma de las ventanas, el estilo de la entrada etc. Si el migrante se disimula o gira su casa hacia el interior en su país de inmigración, se produce lo contrario en su país de pertenencia. La casa tiene que disociarse, mostrarse, ostentar su lujo.

\footnotetext{
${ }^{5}$ El artista Hamid Dabarrah nació en 1954 en Chlef, Argelia; en 1976 se instala en Grenoble, Francia. En 2002, realiza la obra Facies. Inventaires en colaboración con el Centro de los Trabajadores Inmigrantes de la Ciudad. Se trata de una serie de 54 fotografías en blanco y negro de gran formato. Son presentados, en primer lugar, retratos de hombres que no parecen ni de aquí ni ya de allí; y luego, otras fotografías que revelan el entorno de cada uno de ellos, en las cuales observamos maletas al alcance de las manos, closet semivacíos, postales, fotografías del país, etc.
}

Intercom - RBCC

São Paulo, v.35, n.2, p. 169-188, jul./dez. 2012

177 


\section{CÉLIA RIBOULET}

¿Qué quiere mostrar el migrante a través de esta casa si no la habita? Lo que lleva al migrante a construirla es la importancia de la mirada de los otros, las ganas de contar hasta qué punto ha cambiado. El interior y el exterior de los dos espacios construidos a los dos lados de la frontera confirman un único ensamble residencial, gracias al cual el migrante logra establecer una reflexión sobre su trayectoria de vida. La casa funciona como un objeto para verse y para ser visto.

\section{Tiempo y migración}

Una dimensión, no enunciada pero siempre subyacente en esta cuestión de la migración, es la del TIEMPO. La migración está concebida no sólo como un movimiento en el espacio, sino esencialmente como un movimiento en el tiempo. Como lo señala también Miguel A. Hernández Navarro en su artículo "Desincronizados: tiempos migratorios e imágenes del desplazamiento" (2008), las metáforas de la migración suelen tener que ver sobre todo con el lugar. El vocabulario utilizado tiene que ver con metáforas espaciales: tierra, hogar, frontera, distancia, etc. Sin embrago, mientras nos desplazamos, nos cambiamos de lugar; no sólo eso implica una cuestión de espacio, sino también de tiempo. Como lo sugiere Mieke Bal: "la migración también consiste en la experiencia del tiempo como múltiple y heterogéneo. El tiempo de la prisa y de la espera, el tiempo del movimiento y del estancamiento; el tiempo de la memoria y de un presente intranquilizador (BAL, 2008, p.34)".

La instalación video de Gautam Kansara, Don't hurry, don't worry, realizada en $2010^{6}$, explora el espacio íntimo de la casa familiar y de sus recuerdos.

${ }^{6}$ KANSARA, Gautam, Don't hurry, don't worry, (video instalacion) 2010, 1 channel o 4 channel, 14min58s., son., color. Disponible en: http:// gautamkansara.wordpress.com/category/video-installation/ 


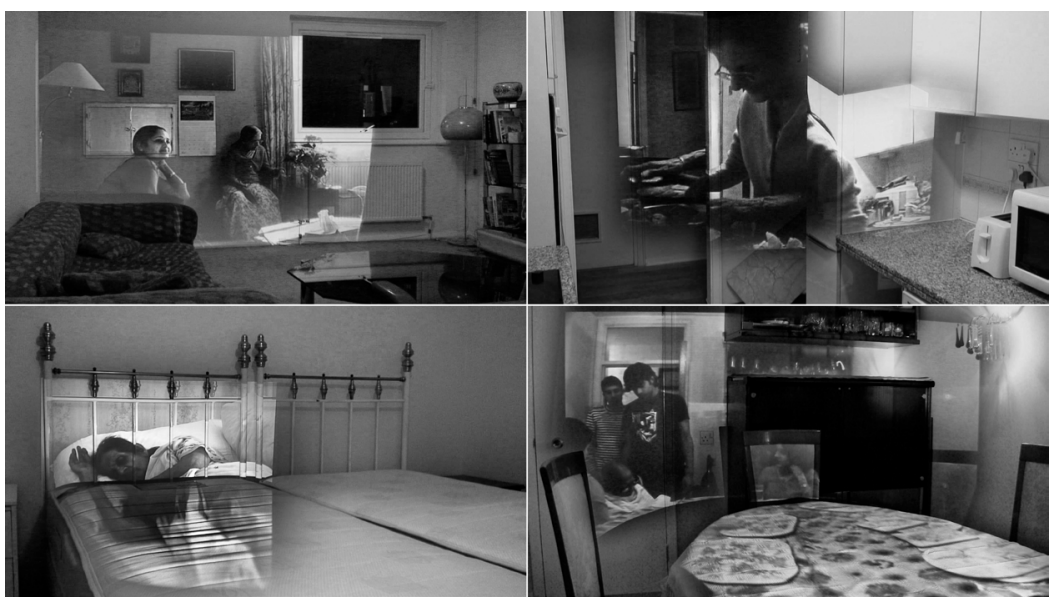

El artista nace en 1970 en Londres, Inglaterra, y emigra a Estados Unidos, en donde vive y trabaja actualmente. Durante seis años, grabó (en el departamento de su abuelo en Londres), la vida cotidiana de su familia. Y luego, en su obra final, proyecta, en los mismos espacios, las escenas grabadas: su abuela cocinando o sentada en la sala, o durmiendo en su cuarto. Si la obra no trata en sí el tema de la migración, trata de otro tema relativo a éste: el tiempo y el alejamiento en las diferentes generaciones de migrantes. La videoinstalación reconstruye una casa construida de hechos, gestos, sensaciones, la casa se transforma en un espacio-memoria. La instalación rompe con el trazado lineal del tiempo para realizar un movimiento circular, un retorno a lo que ya fue y provoca entonces una especie de "bucle" temporal. Si la imagen es primordial en este trabajo, no hay que soslayar la fuerza del sonido que habita, al igual que las imágenes, los recuerdos proyectados. La voz de su abuela, los gritos del abuelo y la música hindú que nos recuerda otra migración, la de los abuelos, que dejaron India por Inglaterra unas décadas atrás. La misma posición de la abuela, sentada al lado de una ventana que abre la vista sobre otra pared con la música hindú de fondo, nos remite a un país y un tiempo lejanos, de una pertenencia pasada que insite sobre los recuerdos de diferentes generaciones de migrantes.

Los gestos de los familiares del artista incrustados en el espacio de la casa plantean otra pregunta relativa al tema de la casa: ¿Qué 


\section{CÉLIA RIBOULET}

relaciones entre una casa y una manera? ("Residencia y manera, patria y estilo" escribe Deleuze). ¿Porque el habitar remite a un tener y a un modal? La hipótesis que retomo de Benoît Goetz es la siguiente: el habitar se declina en la forma del gestare. Es decir que habitamos un espacio cuando nuestra manera de ser se moldea a su frecuentación. La posición y el gesto son elementos esenciales a una teoría del habitar. Como lo escribe J. Derrida, "habitar, es lo que un sujeto hace, decide o "actúa" lo menos, no es una acción". Habitar, es enlazar posiciones y gestos, sin fin. Entonces, habitar es frecuentar de tal manera que un habitus se constituye. "La casa que habito, ella me habita, no necesito escucharla, nos entendemos" (LYOTARD, 1988, 258) Son estos habitus que retrata Gautam Kansara en su instalación. Porque la casa está compuesta de hechos y posturas.

De hechos y posturas y también de hablar, de voces, de lenguas y de idiomas. La obra Mother tongue (2002) ${ }^{7}$ de la artista francesa de origen argelino, Zineb Sedira (la cual vive en Londres), cuestiona este hablar a través de diferentes generaciones de migrantes.

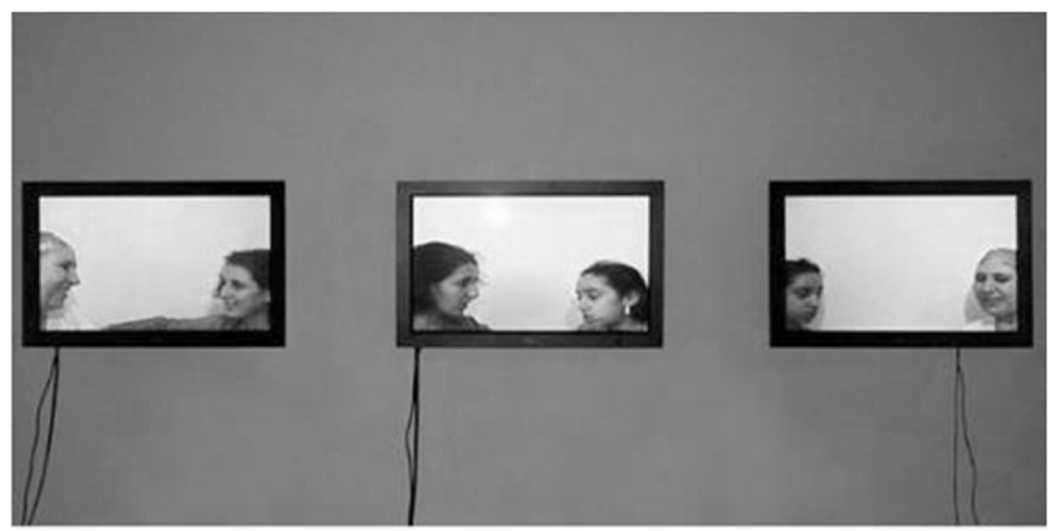

Como lo dice la artista, "mi obra explora las paradojas y las intersecciones de mi identidad como argelina y francesa y también como residente en Inglaterra" (RENARD, 2007, p.19). Su historia personal y la de su familia que dejó Argelia por ir a Francia es el motor de sus creaciones. Mother tongue es una instalación de 3 mo-

\footnotetext{
${ }^{7}$ SEDIRA, Zineb, Mother tongue, 2002, Francia, Inglatera, Algeria, 3 channels, instalación con audífonos, 5 min. ; son., color. Disponible en : http://www.zinebsedira.com/video/mother-tongue-2002
} 
nitores en los cuales se enfrentan en cada pantalla 3 generaciones de mujeres: la artista, su madre y su hija, las cuales dialogan de dos en dos, cada una en su lengua materna. El francés por parte de Zineb, el árabe por su madre y el inglés por la nieta. Historias de escuelas se transmiten de una a otra, pero la narración parece interrumpida entre la abuela y la nieta, que no entiende una la lengua de la otra. El mismo espectador experimenta una sensación parecida a la de los personajes del video; los tres idiomas, el árabe, el inglés y el francés se transmiten sin subtítulos. Si entendemos las preguntas de una, podemos no entender las respuestas de la otra y viceversa, lo que dispersa la primera narración (la de historias de escuelas) para llevarla a un juego verbal y temporal en el cual el idioma no permite una comunicación entre diferentes generaciones de una misma familia, ofreciendo un vacío inestable.

La misma instalación dividida en tres monitores insiste sobre estas fracciones, la abuela se encuentra en los dos extremos de la instalación, entre ella se encuentra su hija de un lado y su nieta del otro. Cada pantalla remite a un espacio tiempo distinto: el de la artista con su madre a Francia y a la educación de ella misma; el de la artista con su hija a Francia e Inglaterra, y el de la nieta y la abuela a un espacio tiempo diluido, indistinto, perdido entre Argelia e Inglaterra.

\section{Información e migración}

Las tres obras estudiadas tienen la característica común de haber sido realizadas por un artista migrante: Tomas Ochoa (Ecuatoriano viviendo en Suiza y Ecuador), Gautam Kansara (Ingles de origen Hindú viviendo en Estados Unidos) y Zineb Sedira (Francesa de origen argelina viviendo en Londres). ¿Como el artista no migrante puede proponer una reflexión desde su lugar a partir de las problemáticas relativas a este tema? Daniel Lupión ${ }^{8}$, propone una obra que pone en duda los modos de comunicación y de conocimiento convencional (la entrevista) acerca de las formas de análisis y de presentación del migrante hacia el mundo.

\footnotetext{
${ }^{8}$ LUPION, Daniel, Entrevistándome con emigrantes, 2002. Vídeo mono-canal. 13'10", son., color.
} 


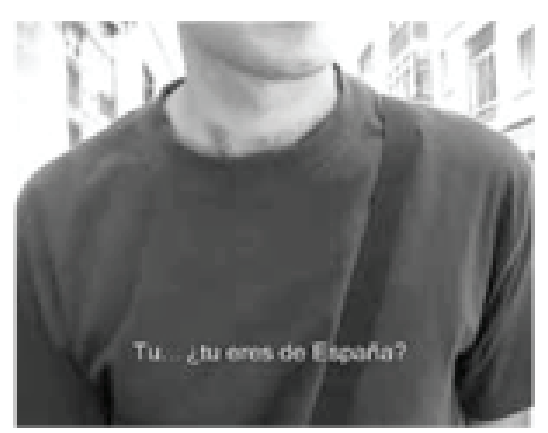

Durante dos semanas, el artista salió a las calles de Madrid con una cámara para entrevistar a inmigrantes. Pero en lugar de realizar las preguntas y enfocar al otro, el artista ofrece la cámara al inmigrante y le sugiere que sea el quien haga las preguntas. Lo que escuchamos es solamente la voz del migrante que pregunta:

"¿De dónde eres?

¿Eres español?

¿Cuánto tiempo llevas aquí?

..." (Lupion, 2011)

Y lo que vemos es al artista grabado por el migrante.

Los dos elementos sonoros y visuales son muy interesantes, cada uno ofrece un punto de vista diferente. En las preguntas hechas por los migrantes, están condensados todos aquellos aspectos que realmente interesan y preocupan al migrante; a saber, cuestiones de origen, de tiempo, de espacio. Y en lo visual, un migrante enfoca, por ejemplo, únicamente el pecho del artista, mientras otro de los entrevistados deja la cámara casi fuera de control cuando comienza la conversación, en este caso, el diálogo supera la visión. Lo visual revela una cierta relación con el mundo.

Si en los países occidentales la imagen se centra en el rostro y en algunas partes del cuerpo, lo que traducen los migrantes, al tener esta utilización de la imagen, es una visión distinta. Miguel A. Hernández Navarro habla de "analfabetismo tecnológico" para caracterizar estas utilizaciones, para definir el uso renovado e impensado de los dispositivos tecnológicos. (HERNÁNDEZ NAVARRO, 2012, p.19). Creo que el término implica un valor 
negativo cuando no se trata exactamente de analfabetismo sino de relación con el mundo, o, retomando las palabras del antropólogo Alain Corbin (1990, p.13), de "modalidades de la percepción", de "jerarquias sensoriales". En realidad, la apuesta fascinante del antropólogo fue saber si era posible distinguir retrospectivamente el modo de presencia del mundo de los hombres del pasado a través del análisis de la jerarquía de los sentidos y del balance establecido entre ellos en un momento dado de la historia y en una sociedad específica. iPero fuera de parloteo, poniéndonos en la situación del migrante, este enfoque puede solamente subrayar este deseo de mantener el anonimato (generalmente ilegal, el migrante prefiere mantener escondido el rostro)!

El desplazamiento realizado por el artista es muy ingenioso. Intercambiando el papel de entrevistador por el de entrevistado, el artista desvía un cierto terrorismo de la pregunta, "en cada pregunta está implicado un poder”, dice Barthes (1978, p.145). ¿Quién hace las preguntas?, el periodista, el maestro, el policía, el encuestador... Para Barthes, el periodista representa una especie de policía que "lo quiere" porque le da la voz, la palabra y le da publicidad. Pero Barthes se pregunta ipor qué responder? Por deontológica social, juego social. Efectivamente, la pregunta nos encierra en una alternativa: responder bien o mal, o no responder por rechazo o ignorancia. Barthes, en su curso del Colegio de Francia, cita el ejemplo de la intriga de la ópera de Puccini (1926) que tiene por trama la boda de la cruel princesa Turandot con aquel hombre que sepa responder los 3 enigmas que ella le propone. Los que están suspendidos estarán decapitados. Mito que ilustra cómo la pregunta puede provocar un encierro que implica locura o drama para el que nos responde.

Así que, por esta vez, es el migrante quien tiene el poder, pero el artista desvía siempre el juego, sólo escuchamos la voz del migrante, el migrante se vuelve de nuevo el entrevistador observado.

\section{Habitar en la migración}

Como último escalón y a modo de conclusión, citaré la obra Migrations del artista norteamericano Doug Aitken?.

\footnotetext{
${ }_{9}^{9}$ AITKEN, Doug, Migrations, (3 channels), 2008, son., color. Disponible en: http://www.youtube.com/watch?v=JZ6cJaGm79E
}

Intercom - RBCC

São Paulo, v.35, n.2, p. 169-188, jul./dez. 2012 

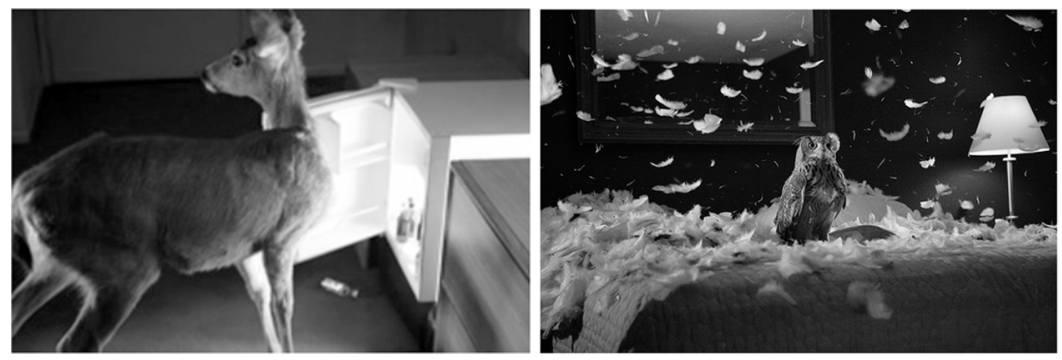

La obra se presenta en tres pantallas instaladas una tras otra, el video que se proyecta es el mismo, presentado con unos segundos de intervalo. Las primeras imágenes plantean el decorado en el cual se desarrolla la acción: paisajes naturales inmensos, algunos invadidos por desarrollos industriales, imágenes de moteles (típicas construcciones arquitecturales estadunidenses). Las imágenes alternan, pero se agrupan según una misma lógica: animales no domésticos experimentan el espacio construido por el hombre. Los animales aparecen solos o por pares, en unos cuartos de hoteles: un búho, dos pavos reales, un búfalo, un caballo, una nutria en una tina, un venado buscando y tirando botellas en un refrigerador. Independientemente del animal, su comportamiento alterna entre observación, intimidación, incomodidad, sorpresa, estupor etc.

La presencia animal en el espacio construido humano enfatiza diversas sensaciones. La primera quizás tiene que ver con la estrechez del espacio, y la segunda con lo "mal" construido que hace referencia a una incompatibilidad del espacio con las necesidades del animal y, por extensión, del humano.

iLa presencia animal enfatiza y problematiza la construcción realizada por el humano, como una "especie de situación arquitectónica esquizofrénica” (ALESSIA DE BIASE, 2008, p.117)? o ipone de relieve las consecuencias de la "civilización" y del desarrollo humano sobre la especie animal?, seguramente las dos al mismo tiempo.

La cuestión se plantea primeramente en términos espaciales, y se podría resumirse así: ¿Qué fundamenta la relación hombre/ espacio? o icómo el espacio se vuelve estructurante de la identidad de los individuos? Esto es lo que analiza la antropóloga Marion Segaud en el libro Antropologie de l'espace. Habiter, fonder, distribuir, 
transformer. En el caso de la obra, ésta plantea y cuestiona, por medio de una arquitectura funcionalista (la de moteles estadounidenses), el triunfo (acompañado de una planificación siempre más compleja y que pone en escena un hombre de necesidades universales) del espacio de tipo universal. Este espacio tipo universal consiste precisamente en unificar el paisaje, ignorando el contexto. Con mucha poesía, la obra explora esta exacerbación del tipo universal de espacio construido por medio de la confrontación inesperada del mundo animal y del mundo humano. Nos podríamos preguntar hasta qué punto el humano modificó su propio entorno para transformarlo en un espacio "alienante" e inadaptado a sus necesidades "vitales".

Podemos, por otro lado, presentar la cuestión en términos históricos, a partir de una reflexión acerca de la colonización y del espacio. C. Levis Strauss establece un paralelo entre hábitat y avasallamiento. En este caso, Levis Strauss demuestra que el hábitat (considerado como un conjunto de prácticas y representaciones) aparece como el garante del conjunto del universo social y cosmogónico de algunas poblaciones de la Amazonía. Pero también el hábitat se puede volver un arma de avasallamiento. Levis Strauss cita el ejemplo de los indios Bororos de la Amazonía, mientras éstos se mantenían en sus pueblos, organizados según una correspondencia estricta entre lugares (los dispositivos espaciales) e individuos, no sucumbían a la conversión cristiana, pero una vez reagrupados a lo largo de una carretera y repartidos en casas a cada lado de la vía, olvidaban rápidamente sus costumbres para adoptar la de los misioneros. En este caso, el espacio es el garante de una estabilidad de organización social, política y espiritual. El espacio participa en la estructura del ser y en su desarrollo. Es relevante en este punto cuestionar la multiplicación de las casas de dos niveles para una familia, situadas en suburbios y aglutinadas una sobre otra, tipo casas "geo". ¿Cuál sería el objetivo? Sobre todo cuando sabemos que, por citar a México, este tipo de casas son las únicas que se adquieren por medio de un plan de préstamo social ofrecido por el gobierno.

De regreso a la obra, es notable también señalar la pérdida de referencia, la estabilización de los animales debido a su aislamiento. 
Estas construcciones están hechas por una "pareja" y no por una tribu, como lo acostumbra la vida animal y quizás humana. Esta insistencia se encuentra en las imágenes del caballo. Mientras el caballo descubre este nuevo espacio, se proyectan en el televisor imágenes de caballos salvajes corriendo, igual en las imágenes de los pavos reales aparecen miles y miles de pájaros volando, quizás migrando. El aislamiento de los animales, en unos espacios inadaptados, genera un cuestionamiento profundo sobre nuestras maneras de vivir y nuestras construcciones. Y nos recuerda unos versos de Holderlïn:

\section{"Lleno de méritos, pero poéticamente, el hombre habita esta tierra."}

¿Qué significaría habitar la tierra poéticamente? Tomamos el tópico común de que los hombres y mujeres de la modernidad industrial ya no habitan el mundo poéticamente, habitar el mundo así tendría que ver con el recuerdo de los mundos vivos. A este propósito, podemos citar la conferencia de Michel Tibon- Cornillot intitulada: "Se souvenir des mondes vivants. A propos de l'interminable fin des societes industrielles":

El mundo real debe de ser reconstruido... y lo es a golpe de buldózer, de bombas, de fábricas, de tractores, de pesticidas. Pero lo es también gracias a las matemáticas y a las ciencias modernas, gracias por fin a las máquinas, robots, computadoras. No se trata solamente de pensar el mundo racionalmente sino de reconstruirlo con el fin de que se vuelva... racional. Sin embargo, el porvenir racional del mundo reconstruido tiende a unificarse, entre pensamiento y acción, y a organizarse unilateralmente como el único mundo posible. Allí donde se incrustan modos de vida fundados sobre el trabajo industrial, sobre los transportes colectivos, y horarios estrictos, sobre hábitat racionales, se organiza sin retrospectiva el único verdadero mundo que cada uno y todos debemos recorrer... porque ya no existen otros. ¿Sería necesario recordar que los orígenes más profundos de la tiranía no consisten en la presencia visible, demasiada visible de las coerciones pero en el olvido aceptado interiorizado de otros mundos, de los que fueron engullidos, pero también de los que, sin embargo, son siempre posibles? (TIBON, 2008, p.195).

Esta obra de Doug Aitken propone un real y profundo cuestionamiento de nuestra manera de habitar el mundo y de nuestra manera de imponerlo a todos los seres vivos. Migraciones, las que 
tienen que ver con el cambio de hábitat y, por consecuencia, de costumbres, de valores que cuestionan una sociabilidad que se encuentra modificada (a través de la transformación del espacio tradicional) en un espacio concebido con el fin de llevarlos (humanos y animales) a la "civilización".

Lo que se teje a través de esta selección de obras videográficas es una cartografía original, critica, plural y viva que relaciona, significa y explora los nudos de identidades liminales, frágiles en un contexto migratorio cada vez mas denso y complejo. Cuestionamientos relativos a las "practicas" migratorias surgen del encuentro entre ficciones, narrativas íntimas, mitos, imágenes, poesías visuales, históricas, anecdóticas, que conforman, entre ficción y documental, estas propuestas videoartísticas lúcidas e interrogativas.

Como investigadores y actores sociales, los artistas excavaron y detallaron las historias, los hechos políticos, las tácticas, para presentar nuevas versiones, sentidos, voces. Las obras cuestionan la conformación y el mantenimiento de la identidad del migrante consecuente con sus desplazamientos. Como lo pudimos ver, la casa, el tiempo, el alejamiento, cristalizan los cuestionamientos de los artistas.

El título del artículo "Migraciones visuales" se refiere justamente a esta mirada critica y a este deseo de comunicación. La migración se vuelve visual y visible a través de este proceso de puesto en imagen y en cuestionamiento de parte de estos artistas. Sea en el caso de Tomas Ochoa que propone a partir de unas entrevistas con migrantes en España una reflexión acerca de "la casa ideal" , o en la obra de Zineb Sedira que a partir de la experiencia del lenguaje y de la lengua en su propia familia de migrantes analiza una ruptura comunicativa y generacional, o en la obra de Doug Aitken que metafóricamente simula una experiencia de migraciones en espacios y construcciones inadaptados; las obras desplazan y cuestionan poéticamente, desde otro punto de vista y de enunciación, unas de las problemáticas relativas a la condición del migrante en nuestros días.

\section{Referencias}

ADORNO, Theodor W. Minima moralia, reflexions sur la vie mutilée. Paris: Payot, 1980.

Intercom - RBCC

São Paulo, v.35, n.2, p. 169-188, jul./dez. 2012 


\section{CÉLIA RIBOULET}

BAL, Mieke, Double mouvement. In : BAL, Mieke; HERNANDEZ-NAVARRO, Miguel. 2Move:Video Art Migration. Murcia: Cendeac, 2008.

BARTHES, Roland. Le neutre, cours au Collège de France (1977-1978). Paris: Ed. Seuil, 2002.

BERQUE, Auguste; DE BIASE, Alessia; BONNIN, Philippe. L'habiter dans sa poétique première, Actos del congreso de Cerisy-la-Salle. Paris: ed. Donner lieu, 2008.

CALDERON-BONY, Frida, La maison du migrant: intimité et altérité de l'espace. E-migrinter, v.4, 2009.

CORBIN, Alain. Histoire et anthropologie sensorielle. In: Anthropologie et Sociétés, vol 14 n 2, p 13-24, 1990. Disponible en http://id.erudit.org/ iderudit/015125ar. Acceso: 29 nov. 2012.

DE BIASE, Alessia. Habiter la nostalgie. In : BERQUE, Auguste; DE BIASE, Alessia; BONNIN, Philippe. L'habiter dans sa poétique première, Actos del congreso de Cerisy-la-Salle. Paris: Donner lieu, 2008.

GOETZ, Benoît. Théorie des maisons. L'habitation, la surprise. Lagrasse: Verdier, 2011.

HEIDEGGER, Martin. Hebel ou l'ami de la Maison. Questions III, Paris, Gallimard, 1990.

HERNANDEZ-NAVARRO, Miguel A. Desincronizados: Tiempos migratorios e imágenes del desplazamiento. Arte y politicas de identidad, v.2 (diciembre), 2010.

LUPION, Daniel. Desplazamientos. 2011. Disponible en

http:/desplazamientos.wordpress.com/category/daniel-lupion-entrevistandome-con-emigrantes/. Acesso em: 29 nov. 2012.

LYOTARD, Jean François. Domus et la Mégapole. Linhumain, Paris: Galilée, 1988.

SEGAUD, Marion. Anthropologie de l'espace, Habiter, Fonder, Distribuer, transformer. Paris: Armand Colin, 2007.

RENARD, Isabelle. Lorsque l'art contemporain réinterroge l'histoire. Hommes \& migrations, n. 1267, p.16- $27,2007$.

TIBON CORNILLOT, Michel. Se souvenir des mondes vivants: à propos de l'interminable fin des sociétés industrielles. In: BERQUE, Auguste; DE BIASE, Alessia; BONNIN, Philippe. L'habiter dans sa poétique première, Actos del congreso de Cerisy-la-Salle. Paris: ed. Donner lieu, 2008.

Recebido: 19. 09.2012

Aceito: 29.11.2012

188

Intercom - RBCC

São Paulo, v.35, n.2, p. 169-188, jul./dez. 2012 